\title{
Competencias que configuran el perfil del docente de primaria. Análisis de la opinión del alumnado de Grado en Educación Primaria
}

\author{
M. Ángeles Valdemoros-San-Emeterio ${ }^{\mathrm{a}, *}$ y Beatriz Lucas-Molina ${ }^{\mathrm{b}}$ \\ aUniversidad de La Rioja, España \\ 'Universidad de Valencia, España
}

INFORMACIÓN DEL ARTÍCULO

Historia del artículo:

Recibido el 10 de diciembre de 2012

Aceptado el 4 de diciembre de 2013

\section{Palabras clave:}

Espacio Europeo de Educación Superior

Grado en Educación Primaria

Opinión del alumnado

Perfil docente

\begin{abstract}
RES U M EN
El objeto del presente estudio se centra en conocer la opinión del alumnado de la primera promoción del Grado en Educación Primaria de la Universidad de La Rioja $(\mathrm{n}=105)$ sobre las competencias que configuran el perfil del docente, con el fin de contrastarla con los resultados que nos brinda la investigación y esbozar propuestas para la formación de los futuros maestros. Para tal fin se diseña y administra un autoinforme integrado por diferentes atributos presentados en un formato de respuesta de tipo Likert. Los resultados han derivado en dos escalas; la primera determina el ser del docente y se agrupa en competencias para saber hacer y en competencias afectivo-emocionales; la segunda alude al tener del docente y en ella se encierran las competencias instrumentales, así como las que aluden al espíritu formativo y a la personalidad del docente. Se pone de manifiesto un mayor grado de acuerdo con las competencias que se refieren al dominio de los saberes y los instrumentos requeridos para la práctica educativa que son, en definitiva, aquellas susceptibles de adquirir y de educar aunque a priori no se posean.
\end{abstract}

(c) 2012 Instituto de Ciencias de la Educación de la Universidad de Oviedo. Publicado por Elsevier España, S.L. Todos los derechos reservados.

\section{Competency Profile of the Elementary School Teacher. Analysis of Pre-service Elementary School Teacher's Opinion}

\author{
A B S T R A C T
}

The purpose of this study was to examine the opinion of pre-service Elementary School Teachers from the University of La Rioja ( $n=105)$ on the teacher competency profile, in order to compare it with the results from previous studies, and to outline proposals for the training of future teachers. To this end, a Likert response self-report questionnaire consisting of different attributes was designed and administered to the students. Two different scales were found: One, related to the 'teacher being' competencies, composed by the 'knowing how to do something' and the affective-emotional skills; and a second one, concerned the 'teacher having' competencies, that referred to the instrumental skills, as well as to the teachers' spirit of learning and personality. A greater agreement with those skills related to the knowledge and management of different teaching practices was found among the students. This result highlights the importance given by students to those skills that, although not been initially held, can be acquired and improved through a training process. (c) 2012 Instituto de Ciencias de la Educación de la Universidad de Oviedo. Published by Elsevier España, S.L. All rights reserved.

\section{Introducción}

El modelo de formación académica en el Espacio Europeo de Educación Superior (EEES) traslada el foco de atención de la enseñanza hacia el aprendizaje (Fidalgo y García, 2007; Guth, 2006; Zabalza,

\footnotetext{
*Autor para correspondencia: M. Ángeles Valdemoros-San-Emeterio.

Universidad de La Rioja. C/ Luis de Ulloa, s/n (Edificio Vives).

CP 26002, Logroño (España).

Correo electrónico: maria-de-los-angeles.valdemoros@unirioja.es
}

2007), lo que requiere de una transformación de las pautas pedagógicas del profesorado (Cifuentes, 2008) y establece, por ende, al alumnado en agente activo que construye su conocimiento.

Rodríguez, Álvarez, Gil y Romero (2011) ponen de manifiesto ciertas necesidades de formación relacionadas con la enseñanza que requiere el EEES, vinculadas a la adecuada identificación de las competencias profesionales, la discriminación apropiada de contenidos o el manejo de técnicas de evaluación de competencias. A su vez, Cardona (2011) constata que el alumnado critica que al culminar su formación adolece de falta de integración entre el saber teórico y el 
práctico, de inseguridad en la toma de decisiones en situaciones educativas complejas, así como en el diseño e implementación de programas para la intervención pedagógica.

Zabalza (2003) define el término competencia como la suma de saberes éticos, vivenciales, cognitivos, emotivos y prácticos, necesarios para que el profesional pueda llevar a cabo roles de trabajo específicos y realizar actividades encaminadas al logro de objetivos determinados.

Los futuros docentes requieren de competencias que trasciendan la transmisión de conocimientos, con el fin de ajustar su perfil a la realidad que configura la sociedad actual (Liesa y Vived, 2010), por lo que los aspectos afectivos, traducidos en implicación personal, emocional y moral, han de constituir uno de los ejes conductores que desemboque en una realización integral de la tarea docente (Zahonero y Martín, 2012).

Se coincide con Zabalza (2012) en que la formación del profesorado ha de insertarse en un enfoque humanista de las competencias, que capacite para operar en contextos de aprendizaje que vinculen teoría y práctica, que posibilite resolver problemas derivados de la práctica educativa y viabilice el ejercicio docente en la etapa para la que se está formando.

La titulación de Grado en Educación Primaria de la Universidad de La Rioja cuenta con la experiencia de tres cursos académicos de implantación del Plan Bolonia, período en el que se evidencia una necesidad de cambio en la mentalidad pedagógica, que se pone de manifiesto con la incorporación de nuevas materias, el establecimiento de distintas formas de agrupamiento y el incremento de la formación práctica del estudiantado, entre otras cuestiones.

Una de las nuevas asignaturas que contribuye a esta formación práctica es la que corresponde a Prácticas Escolares, perteneciente al módulo de Prácticum y Trabajo Fin de Grado de Educación Primaria y a la materia de Prácticas Escolares. Esta asignatura se desarrolla a través de 6,5 créditos ECTS (Sistema Europeo de Transferencia y Acumulación de Créditos) y contribuye a afianzar la formación del futuro profesional de la educación a nivel psicopedagógico y epistemológico, así como a contextualizar los contenidos teóricos ofrecidos en las aulas universitarias.

La formación del futuro docente debe potenciar una reflexión crítica y comprometida con la calidad de su desempeño en un ambiente participativo y dialógico (González-Tirados y González-Maura, 2007), dado que algunas investigaciones verifican la existencia de puntos débiles en diversas capacidades de los estudiantes de algunas titulaciones relacionadas con las ciencias de la educación. Éste es el caso de la organización y la planificación, la adaptación al lugar de trabajo, la localización, el análisis y síntesis de la información, la resolución de problemas, la creatividad, el trabajo autónomo, la iniciativa o el trabajo colaborativo (Rodicio e Iglesias, 2011), un insuficiente progreso de competencias vinculadas a la cooperación con las familias, la contribución en la gestión de los centros escolares y a la atención a la diversidad (Gutiérrez-García, Pérez-Pueyo, Pérez Gutiérrez y Palacios, 2011), así como una deficiente competencia socioemocional para el desempeño eficaz de la futura labor docente al carecer de las habilidades necesarias para el trabajo en equipo, la conducción de grupos, la adaptación a los incesantes cambios o el control de las emociones (Pertegal, Castejón y Martínez, 2011).

Jordán (2011) pone el énfasis en la urgencia de atender en la formación inicial y permanente del profesorado al trabajo de ciertas actitudes denominadas densas, caso del amor, la responsabilidad y la esperanza pedagógica, dado que constata que la posesión de éstas ejerce una enorme influencia en el progreso académico y formativo del alumnado, además de garantizar la satisfacción plena en la práctica docente.

Para solventar estas carencias, el EEES pretende el progreso de competencias profesionales entre el alumnado de Grado en Educación Primaria. Pero, ¿cuáles son las competencias que deben desarrollarse? Para dar respuesta a este interrogante se considera fundamental examinar la opinión de uno de los principales agentes implicados: el alumnado.

En un estudio llevado a cabo por Pesquero et al. (2008) se constata que las competencias mejor valoradas por los maestros de primaria, por orden de importancia, son: saber implicar a los padres y las madres en el aprendizaje de sus hijos; ser capaces de desarrollar en el alumnado valores como la responsabilidad, la solidaridad y la justicia; $\mathrm{y}$, finalmente, el perfecto dominio de los contenidos de las diferentes áreas de conocimiento que imparten. Respecto a las competencias centradas en los aprendizajes consideran fundamental detectar las dificultades de su alumnado en aprendizajes concretos, ayudarles a encontrar sentido a los contenidos escolares y enfatizar la cooperación entre ellos. En referencia a las habilidades sociales, se destaca la que alude a la resolución de conflictos, y sobre la personalidad del maestro se enfatiza la vocación y la entrega a la profesión.

De interés resultan las conclusiones a las que llegan Marín, Latorre y Blanco (2010), quienes aseveran que los futuros docentes valoran la formación de una conciencia crítica y reflexiva y, sin embargo, no estiman como primordiales ni la formación en las tecnologías de la información y la comunicación ni el aprendizaje de una segunda lengua extranjera como capacidades imprescindibles para su preparación y crecimiento profesional.

A su vez, Larrosa (2010) verifica que las condiciones del ejercicio profesional docente para obtener plena satisfacción son la vocación, la competencia, la actitud de apertura, el servicio a la comunidad, el trabajo en equipos flexibles, la dedicación y, por último, el conocimiento de los deberes y los derechos éticos.

Casero (2010) lleva a cabo una revisión de la bibliografía relacionada con las contribuciones acerca de los elementos que caracterizan el buen ejercicio docente, y establece ocho dimensiones: conocimientos teóricos, estructuración de las clases y los materiales, comunicación, metodología utilizada y motivación docente, trato y respeto con el alumnado, autoevaluación docente y evaluación del alumnado, entorno académico y, por último, aspecto físico y estética. En su investigación destaca como cualidades del profesor universitario, según la percepción del alumnado, por un lado, la importancia que se concede a los aspectos de competencia formal -saber y saber hacer- y, por otro, a aquellas cuestiones más personales -saber ser. Otros aspectos que se enfatizan guardan relación con el dominio de la materia, la explicación clara y ordenada, la capacidad para motivar, el entusiasmo, la humildad y el respeto hacia el alumnado.

Asimismo, Armengol et al. (2007, 2011), en referencia a los profesionales de la educación, dividen las competencias que han de configurar su perfil en tres tipos: instrumentales (dominio de los conocimientos y las herramientas necesarias para desarrollar el ejercicio de la práctica educativa), emocionales (saber gestionar y regular constructivamente la dimensión socioafectiva personal y grupal en el ejercicio de la práctica educativa) y, por último, sociales (saber colaborar con otros profesionales de forma comunicativa y constructiva y mostrar un comportamiento orientado al grupo y al entendimiento interpersonal).

Fuera de nuestras fronteras, Allan, Clarke y Jopling (2009) exploran la percepción de los estudiantes universitarios de educación de primer curso del Reino Unido acerca de lo que significa una enseñanza efectiva, y concluyen que la noción de eficacia se basa menos en la posesión del docente de altas expectativas académicas de su alumnado, y más en la provisión de andamiajes cognitivos y la promoción de una interacción eficaz con los discentes.

En la misma línea, Ng, Nicholas y Williams (2010) constatan que las creencias iniciales de los docentes sobre la enseñanza de calidad evolucionan de una opinión centrada en que ésta se adquiere mediante la experiencia a otra que focaliza la importancia en el carisma del profesor, así como en la construcción de las relaciones con su alumnado.

En síntesis, la formación del docente de la sociedad del siglo xxı ha de enfocarse hacia el logro de competencias intelectuales, profesionales, sociales, interpersonales e intrapersonales (Galvis, 2007) que garanticen el equilibrio emocional, el bienestar psicológico, la satisfacción y el compromiso con la profesión, dado que se constituyen en condiciones necesarias para una práctica profesional de calidad (García, 2010). 
Tabla 1

Síntesis de investigaciones que analizan las competencias del docente

\begin{tabular}{|c|c|c|}
\hline Autores & Título & Conclusiones \\
\hline Rodríguez et al. (2011) & $\begin{array}{l}\text { Necesidades del profesorado de la Universidad de } \\
\text { Sevilla respecto a la enseñanza que requiere el EEES }\end{array}$ & $\begin{array}{l}\text { Identificación de competencias profesionales y técnicas para su evaluación; } \\
\text { discriminación de contenidos }\end{array}$ \\
\hline Cardona (2011) & $\begin{array}{l}\text { Hacia la mejora de la formación práctica del estudiante } \\
\text { de pedagogía en la UNED }\end{array}$ & $\begin{array}{l}\text { Criticas del alumnado acerca de su formación: falta de integración } \\
\text { teoría-práctica, inseguridad en situaciones complejas y en diseño } \\
\text { e implementación de programas }\end{array}$ \\
\hline Liesa et al. (2010) & $\begin{array}{l}\text { El nuevo Prácticum del Grado de Magisterio. } \\
\text { Aportaciones de alumnos y profesores }\end{array}$ & $\begin{array}{l}\text { Los futuros docentes requieren de competencias que trasciendan } \\
\text { la transmisión de conocimientos }\end{array}$ \\
\hline Zahonero et al. (2012) & $\begin{array}{l}\text { Formación integral del profesorado: hacia el desarrollo } \\
\text { de competencias personales y de valores en los docentes }\end{array}$ & Los aspectos afectivos han ser eje conductor en la tarea docente \\
\hline Zabalza (2012) & $\begin{array}{l}\text { Las competencias en la formación del profesorado: } \\
\text { de la teoría a las propuestas prácticas }\end{array}$ & $\begin{array}{l}\text { La formación del profesorado ha de insertarse en un enfoque humanista } \\
\text { de las competencias }\end{array}$ \\
\hline González et al. (2007) & $\begin{array}{l}\text { Diagnóstico de necesidades y estrategias de formación } \\
\text { docente en las universidades }\end{array}$ & $\begin{array}{l}\text { La formación del docente debe potenciar una reflexión crítica } \\
\text { y comprometida, en un entorno dialógico }\end{array}$ \\
\hline Rodicio et al. (2011) & $\begin{array}{l}\text { La formación en competencias a través del prácticum. } \\
\text { Un estudio piloto }\end{array}$ & $\begin{array}{l}\text { Debilidades formativas en: organización y planificación, adaptación al lugar } \\
\text { de trabajo, localización, análisis y síntesis de información, resolución de } \\
\text { problemas, creatividad, trabajo autónomo, iniciativa y trabajo colaborativo }\end{array}$ \\
\hline Gutiérrez et al. (2011) & $\begin{array}{l}\text { Percepciones de profesores y alumnos sobre la enseñanza, } \\
\text { evaluación y desarrollo de competencias en estudios } \\
\text { universitarios de formación de profesorado }\end{array}$ & $\begin{array}{l}\text { Debilidades formativas en competencias para la cooperación con las familias, } \\
\text { gestión de centros y atención a la diversidad }\end{array}$ \\
\hline Pertegal et al. (2011) & $\begin{array}{l}\text { Competencias socioemocionales en el desarrollo } \\
\text { profesional del maestro }\end{array}$ & $\begin{array}{l}\text { Debilidades formativas en competencias socioemocionales (trabajo en equipo, } \\
\text { conducción de grupos, adaptación al cambio y control de emociones) }\end{array}$ \\
\hline Jordán (2011) & $\begin{array}{l}\text { Disposiciones esenciales de los profesores en las relaciones } \\
\text { con sus alumnos desde una perspectiva ético-pedagógica }\end{array}$ & $\begin{array}{l}\text { Necesidad de atender al trabajo de actitudes "densas" (amor, responsabilidad } \\
\text { y esperanza pedagógica) }\end{array}$ \\
\hline Pesquero et al. (2008) & Las competencias profesionales de los maestros de primaria & $\begin{array}{l}\text { Competencias mejor valoradas: saber implicar a las familias, desarrollar } \\
\text { valores, dominar contenidos, detectar dificultades, motivar, resolver } \\
\text { conflictos y tener vocación }\end{array}$ \\
\hline Marín et al. (2010) & $\begin{array}{l}\text { Las competencias profesionales de la titulación de magisterio } \\
\text { vistas desde la óptica del alumno receptor. Estudio del caso } \\
\text { de Educación Primaria }\end{array}$ & Competencia mejor valorada: formación de una conciencia crítica y reflexiva \\
\hline Larrosa (2010) & $\begin{array}{l}\text { Vocación docente frente a profesión docente en las } \\
\text { organizaciones educativas }\end{array}$ & $\begin{array}{l}\text { Condiciones para el ejercicio docente: vocación, apertura, servicio } \\
\text { a la comunidad, trabajo en equipos flexibles, dedicación y conocimiento } \\
\text { de deberes y derechos éticos }\end{array}$ \\
\hline Casero (2010) & ¿Cómo es el buen profesor universitario según el alumnado? & $\begin{array}{l}\text { Cualidades: dominar la materia, explicar clara y ordenadamente, motivar } \\
\text { y ser respetuoso }\end{array}$ \\
\hline Armengol et al. (2011) & $\begin{array}{l}\text { El Prácticum en el EEES: mapa de competencias del profesional } \\
\text { de la educación }\end{array}$ & Competencias instrumentales, emocionales y sociales \\
\hline Allan et al. (2009) & $\begin{array}{l}\text { Effective Teaching in Higher Education: Perceptions of First Year } \\
\text { Undergraduate Students }\end{array}$ & $\begin{array}{l}\text { Importancia de proveer andamiajes cognitivos y promover la interacción } \\
\text { eficaz entre discentes }\end{array}$ \\
\hline $\mathrm{Ng}$ et al. (2010) & $\begin{array}{l}\text { School experience influences on pre-service teachers' evolving } \\
\text { beliefs about effective teaching }\end{array}$ & Importancia del carisma docente y las relaciones con su alumnado \\
\hline Galvis (2007) & $\begin{array}{l}\text { De un perfil docente tradicional a un perfil docente } \\
\text { basado en competencias }\end{array}$ & $\begin{array}{l}\text { Formación docente: competencias intelectuales, profesionales, sociales, } \\
\text { inter- e intrapersonales }\end{array}$ \\
\hline García (2010) & Competencias éticas del profesor y calidad de la educación & $\begin{array}{l}\text { Formación docente: garantizar equilibrio emocional, bienestar psicológico, } \\
\text { satisfacción y compromiso con la profesión }\end{array}$ \\
\hline
\end{tabular}

EEES: Espacio Europeo de Educación Superior; UNED: Universidad Nacional de Educación a Distancia.

La tabla 1 recoge una síntesis de la revisión teórica que sustenta este trabajo.

Desde las aulas universitarias ha de propiciarse una profunda reflexión acerca del perfil docente que ha de caracterizar a los futuros profesionales, con el fin de concienciar al estudiantado de las cualidades que han de configurar su perfil profesional, así como de las diferentes competencias que deberán adquirirse para optimizar su desempeño laboral.

El objeto del presente estudio se centra en conocer la opinión del alumnado de Grado en Educación Primaria sobre las competencias que configuran el perfil del buen docente, con el fin de contrastarla con los resultados que nos brinda la investigación sobre el tema en cuestión y esbozar propuestas de intervención para la formación de los futuros maestros. Asimismo, dado que los estudios analizados no examinan las diferencias por sexos, se pretende averiguar si en la presente investigación se revelan diferencias significativas entre hombres y mujeres.

\section{Método}

\section{Participantes}

Los participantes fueron 105 estudiantes, de edades comprendidas entre los 20 y los 37 años (media [M] = 20,78; desviación típica
$[\mathrm{DT}]=3,05)$, de la primera promoción del Grado en Educación Primaria de la Universidad de la Rioja, iniciada en el curso 2009-2010. El porcentaje de hombres fue del $45,7 \%$ (48) y el de mujeres, del $54,3 \%$ (57). La media de edad para las mujeres fue de 20,79 años, con una desviación típica de 3,44; en el caso de los hombres, los valores eran parecidos, siendo la media de edad 20,77 años, con una desviación típica de 2,56. Para garantizar la equivalencia por sexos en cuanto a la edad, se realizó una prueba de diferencia de medias, y el valor de la $t$ de Student resultante de comparar estas medias fue de $-0,031$, no significativo a un nivel de probabilidad del $5 \%$. La selección de los participantes fue incidental, ya que todos ellos asistían a clases de la asignatura Prácticas Escolares.

\section{Instrumentos}

Para evaluar la opinión del alumnado, se administró un autoinforme elaborado ad hoc, integrado por diferentes atributos relacionados con diversas competencias señaladas por los estudios realizados sobre el perfil del buen docente (Armengol et al., 2007, 2011; Casero, 2010; Larrosa, 2010; Pesquero et al., 2008) y que incluía, a su vez, dos escalas que mostraban atributos que eran presentados en un formato de respuesta tipo Likert de cinco puntos, en el que el 1 reflejaba el mínimo y el 5 el máximo grado de acuerdo. 
Una primera, denominada "El buen docente ha de ser", contenía 16 atributos. El alumnado participante podía elegir entre una de las cinco categorías para indicar su grado de acuerdo con cada una de las 16 características concretas. El conjunto de los 16 elementos alcanzaba un coeficiente alpha de 0,81 (intervalo de confianza [IC] del 95\%: 0,75-0,86), con unos índices de discriminación que oscilaban entre 0,31 y 0,64 .

La segunda escala, denominada "El buen docente ha de tener", estaba compuesta por 10 elementos relacionados con distintas características que ha de poseer el buen docente. Esta escala mostraba un coeficiente alpha de 0,77 (IC del 95\%: 0,70-0,83), y los valores de los índices de discriminación oscilaban entre 0,37 y 0,66.

\section{Procedimiento}

La evaluación fue realizada por las investigadoras, autoras de este trabajo. La aplicación del instrumento fue colectiva y se desarrolló en la misma aula universitaria en horario lectivo, previa explicación de las instrucciones necesarias y poniendo especial énfasis en la confidencialidad de los datos. La participación fue de carácter voluntario, aunque ningún estudiante se negó a la misma.

\section{Análisis de datos}

El análisis de datos se realizó con el programa IBM SPSS Statistics 19, utilizando análisis descriptivos, técnicas de reducción de la dimensionalidad y contrastes de hipótesis para variables continuas. A lo largo de la exposición de los resultados se describirán los estadísticos realizados en cada caso.

\section{Resultados}

\section{Resultados en la escala "El buen docente ha de ser"}

De las 16 competencias evaluadas en esta escala, entre aquellas que presentaron una media más elevada se encuentran: ser capaz de motivar $(4,90)$ y ser respetuoso $(4,90)$, ser capaz de escuchar $(4,86)$, ser capaz de atender la educación en valores $(4,77)$, ser capaz de favorecer la formación integral $(4,74)$ y ser capaz de colaborar con las familias $(4,73)$. En el polo opuesto, las competencias con las medias más bajas, aunque siempre superiores a 3, son: ser amigo de sus alumnos $(3,24)$, ser afectivo $(4,09)$ y ser imparcial $(4,17)$. En la tabla 2 se presentan los porcentajes de respuesta de los participantes en cada una de las cinco categorías de respuesta evaluadas en las 16 competencias de la escala "El buen docente ha de ser".
Con el fin de reducir la dimensionalidad de esta escala, los 16 elementos fueron sometidos a un análisis de componentes principales seguido de rotación Promax, que permite obtener factores correlacionados. A partir de la orientación proporcionada tanto por el criterio de Kaiser (autovalores mayores que uno), como por el Scree test, así como por consideraciones basadas en estudios previos, fueron retenidos dos factores que explicaban el 39,9\% de la varianza total y mostraban una elevada correlación $(r=0,486)$. Estos dos factores resultantes podrían interpretarse como:

- Competencias para saber hacer. Este factor estaba formado por 8 ítems relacionados con cualidades referentes al dominio de las habilidades necesarias para el desempeño de la tarea educativa (p. ej., ser creativo, ser capaz de motivar, ser capaz de establecer límites, ser capaz de favorecer la formación integral, etc.). Este factor mostraba una consistencia interna de 0,74 (IC del $95 \%$ : 0,65-0,81). Los índices de discriminación de los ítems mostraban valores entre 0,40 y 0,65 .

- Competencias afectivo-emocionales. Factor formado por 8 elementos relacionados con saber gestionar y controlar constructivamente el ámbito afectivo y emocional en el ejercicio de la práctica docente (p. ej., ser capaz de escuchar, ser consejero de sus alumnos, ser amigo de sus alumnos, ser afectivo, etc.). El conjunto de los 8 ítems alcanzaba un coeficiente alpha de 0,68 (IC del 95\%: 0,57-0,76), con unos índices de discriminación que oscilaban entre 0,38 y 0,51.

Tabla 3

Matriz factorial rotada de los ítems referidos a "El buen docente ha de ser"

\begin{tabular}{lcc}
\hline & \multicolumn{2}{c}{ Factor } \\
\cline { 2 - 3 } & 1 & 2 \\
\hline Creativo & 0,560 & 0,688 \\
Capaz de escuchar & & 0,499 \\
Consejero de sus alumnos & & 0,597 \\
Amigo de sus alumnos & & 0,312 \\
Capaz de adaptarse permanentemente a los cambios & & 0,738 \\
Afectivo & & 0,572 \\
Empático & & 0,387 \\
Respetuoso & 0,530 & \\
Capaz de establecer límites & 0,896 & \\
Capaz de motivar & 0,738 & \\
Capaz de favorecer la formación integral & 0,727 & \\
Capaz de atender la educación en valores & 0,465 & \\
Paciente & 0,619 & \\
Capaz de colaborar con las familias & 0,317 & \\
Imparcial & & 0,416 \\
Entusiasta & & \\
\hline
\end{tabular}

Notas. Método de extracción: análisis de componentes principales. Método de rotación: normalización Promax con Kaiser. Se han eliminado las saturaciones inferiores a 0,30.

Tabla 2

Porcentajes de respuesta en las competencias sobre "El buen docente ha de ser"

\begin{tabular}{|c|c|c|c|c|c|}
\hline & $\begin{array}{l}\text { Totalmente } \\
\text { en desacuerdo }\end{array}$ & En desacuerdo & $\begin{array}{l}\text { Ni de acuerdo } \\
\text { ni en desacuerdo }\end{array}$ & De acuerdo & $\begin{array}{l}\text { Totalmente } \\
\text { de acuerdo }\end{array}$ \\
\hline Creativo & 0 & 0 & 1,9 & 35,2 & 62,9 \\
\hline Capaz de escuchar & 0 & 0 & 0 & 13,3 & 86,7 \\
\hline Consejero de sus alumnos & 1 & 0 & 13,3 & 28,6 & 57,1 \\
\hline Amigo de sus alumnos & 4,8 & 13,3 & 48,6 & 18,1 & 15,2 \\
\hline Capaz de adaptarse permanentemente a los cambios & 0 & 0 & 7,6 & 32,4 & 60 \\
\hline Afectivo & 0 & 2,9 & 14,3 & 41,9 & 41,0 \\
\hline Empático & 1 & 0 & 2,9 & 29,5 & 66,7 \\
\hline Respetuoso & 0 & 0 & 1 & 8,6 & 90,5 \\
\hline Capaz de establecer límites & 0 & 0 & 1 & 27,6 & 71,4 \\
\hline Capaz de motivar & 0 & 0 & 0 & 11,4 & 88,6 \\
\hline Capaz de favorecer la formación integral & 0 & 0 & 2,9 & 21 & 76,2 \\
\hline Capaz de atender la educación en valores & 0 & 0 & 1 & 20 & 79 \\
\hline Paciente & 0 & 0 & 1,9 & 23,8 & 74,3 \\
\hline Capaz de colaborar con las familias & 0 & 0 & 1,9 & 19 & 79 \\
\hline Imparcial & 1,9 & 1,9 & 17,1 & 28,6 & 50,5 \\
\hline Entusiasta & 0 & 0 & 13,3 & 31,4 & 55,2 \\
\hline
\end{tabular}




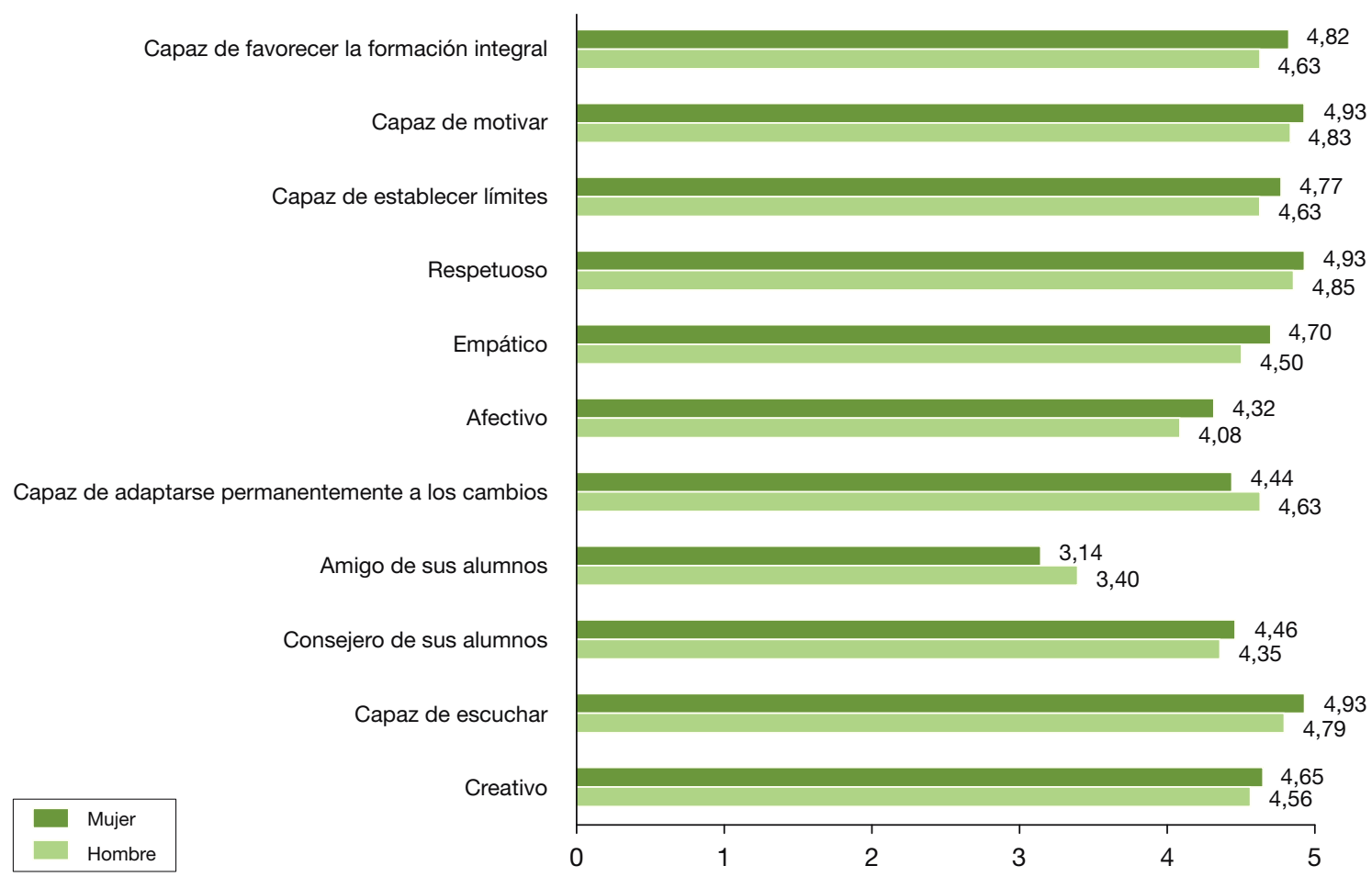

Figura 1. Comparación de medias en los componentes de la escala "El buen docente ha de ser" en función del sexo.

En la tabla 3 se presenta la matriz factorial rotada con las saturaciones de las características en cada factor.

Respecto a las dos categorías de competencias obtenidas en la escala "El buen docente ha de ser", la puntuación media obtenida en competencias para el saber hacer $(M=4,68$; $D T=0,32)$ fue superior a la obtenida en competencias afectivo-emocionales $(\mathrm{M}=4,40$; $\mathrm{DT}=0,39$ ), lo que refleja que el alumnado poseía un mayor grado de acuerdo con el primer tipo de competencias. El estadístico $t$ de Student para muestras relacionadas reflejó que estas diferencias eran estadísticamente significativas $(t(104)=8,478 ; p<0,001)$.

Con el fin de analizar posibles diferencias de género en el grado de acuerdo en las 16 competencias analizadas de forma separada, así como agrupadas en cada uno de los dos factores, se utilizó el estadístico de contraste $t$ de Student para muestras independientes.

En la figura 1 se presentan las medias para cada una de las 16 competencias para hombres y mujeres. Comparando las medias obtenidas en cada competencia se encontraron diferencias significativas en las siguientes competencias: las mujeres obtuvieron puntuaciones superiores en ser capaz de escuchar $(t(76,33)=-2,021 ; p<0,05)$ y ser capaz de favorecer la formación integral $(t(85,96)=-1,999 ; p<0,05)$. No se hallaron diferencias significativas entre hombres y mujeres en el resto de competencias estudiadas.

En la tabla 4 se presentan las medias y las desviaciones típicas obtenidas por hombres y mujeres en las dos categorías de competencias encontradas: para el saber hacer y afectivo-emocionales. El estadístico $t$ de Student no detectó la existencia de diferencias signi-

\section{Tabla 4}

Medias y desviaciones típicas en los factores de la escala "El docente ha de ser" por sexos

\begin{tabular}{lllllll}
\hline & & \multicolumn{2}{l}{ Competencias saber hacer } & & \multicolumn{2}{l}{ Competencias afectivo-emocionales } \\
Sexo & N.o & M & DT & & M & DT \\
\hline Hombre & 48 & 4,61 & 0,36 & & 4,36 & 0,42 \\
Mujer & 57 & 4,73 & 0,28 & & 4,43 & 0,37 \\
\hline
\end{tabular}

ficativas en ambos factores en función del sexo. Sin embargo, sí reveló una tendencia según la cual las mujeres mostraban un mayor grado de acuerdo que los hombres en las competencias para el saber hacer $(t(103)=-1,956 ; p=0,053)$.

\section{Resultados en la escala "El buen docente ha de tener"}

De los 10 elementos que incluía esta segunda escala, entre aquellos que presentaron una media más elevada se encuentran: tener pasión por enseñar $(4,78)$, tener espíritu de formación continua $(4,67)$ y tener conocimiento de metodologías diversas $(4,53)$. Las medias más bajas, siendo siempre superiores a 3 puntos, se hallaron en los siguientes ítems: tener unas características de personalidad especiales $(3,58)$, tener autoridad $(4,27)$ y tener carisma y capacidad de persuasión $(4,29)$. Si se comparan estas medias con las obtenidas en los componentes de la escala "El buen docente ha de ser", puede decirse que son, a nivel general, más bajas. En la tabla 5 se presentan los porcentajes de respuesta de los participantes en cada uno de los cinco grados de acuerdo evaluados en las 10 competencias sobre "El buen docente ha de tener".

Para esta escala, el análisis de componentes principales seguido de rotación Promax,reveló la existencia de dos factores que explicaban el $47,37 \%$ de la varianza total y estaban moderadamente relacionados $(r=0,426)$. Estos dos factores podrían interpretarse del siguiente modo:

- Competencias instrumentales y espíritu formativo. Factor formado por 6 ítems, la mayoría de ellos relacionados con el dominio de los conocimientos y las herramientas necesarias para desarrollar el ejercicio de la práctica docente, así como con una predisposición a la formación permanente (p. ej., espíritu de formación continua, formación generalista y específica, espíritu crítico, etc.). Los 6 ítems alcanzaban una consistencia interna de 0,75 (IC del 95\%: 0,66-0,81), con unos índices de discriminación que oscilaban entre 0,42 y 0,60.

- Personalidad del docente. Este factor estaba formado por 4 ítems, relacionados con la idiosincrasia que marca el carácter y el tem- 
Tabla 5

Porcentajes de respuesta en las competencias sobre "El buen docente ha de tener"

\begin{tabular}{|c|c|c|c|c|c|}
\hline & $\begin{array}{l}\text { Totalmente } \\
\text { en desacuerdo }\end{array}$ & En desacuerdo & $\begin{array}{l}\text { Ni de acuerdo } \\
\text { ni en desacuerdo }\end{array}$ & De acuerdo & $\begin{array}{l}\text { Totalmente } \\
\text { de acuerdo }\end{array}$ \\
\hline Espíritu de formación continua & 0 & 0 & 1,9 & 29,5 & 68,6 \\
\hline Formación generalista y específica & 0 & 1 & 9,5 & 41 & 47,6 \\
\hline Formación psicopedagógica de la etapa educativa implicada & 0 & 0 & 11,4 & 43,8 & 44,8 \\
\hline Manejo de las tecnologías de la información y la comunicación & 0 & 0 & 9,5 & 36,2 & 54,3 \\
\hline Autoridad & 0 & 1,9 & 10,5 & 46,7 & 41 \\
\hline Actitud inclusiva & 0 & 0 & 3,8 & 31,4 & 64,8 \\
\hline Espíritu crítico & 1 & 0 & 5,7 & 45,7 & 48,6 \\
\hline Pasión por enseñar & 0 & 0 & 1 & 20 & 79 \\
\hline Conocimiento de metodologías diversas & 0 & 0 & 5,7 & 35,2 & 59 \\
\hline Carisma y capacidad de persuasión & 0 & 1 & 9,5 & 49,5 & 40 \\
\hline Unas características de personalidad especiales & 3,8 & 9,5 & 32,4 & 33,3 & 21 \\
\hline
\end{tabular}

peramento distintivo y propio del docente (p. ej., carisma y capacidad de persuasión, autoridad, pasión por enseñar, etc.). El coeficiente alpha, muy influido por el número de elementos, alcanza en este factor un valor de 0,58 (IC del 95\%: 0,43-0,70). Los índices de discriminación oscilaban entre 0,30 y 0,51.

Tabla 6

Matriz factorial rotada de los ítems referidos a "El buen docente ha de tener"

\begin{tabular}{lll}
\hline & \multicolumn{2}{l}{ Factor } \\
\cline { 2 - 3 } & 1 & 2 \\
\hline Espíritu de formación continua & & 0,862 \\
Formación generalista y específica & & 0,810 \\
Formación psicopedagógica de la etapa evolutiva implicada & & 0,665 \\
Manejo de las tecnologías de la información y la comunicación & & 0,354 \\
Autoridad & 0,727 & \\
Espíritu crítico & & 0,440 \\
Pasión por enseñar & 0,444 & \\
Conocimiento de metodologías diversas & \multicolumn{2}{c}{0,304} \\
Carisma y capacidad de persuasión & 0,781 & \\
Unas características de personalidad especiales & 0,679 & \\
\hline
\end{tabular}

Notas. Método de extracción: análisis de componentes principales. Método de rotación: normalización Promax con Kaiser. Se han eliminado las saturaciones inferiores a 0,30.
En la tabla 6 se presenta la matriz factorial rotada con las saturaciones de las características en cada factor.

En cuanto a los dos factores obtenidos en esta escala, la puntuación media obtenida en competencias instrumentales y espíritu formativo $(\mathrm{M}=4,47 ; \mathrm{DT}=0,43)$ fue superior a la obtenida en personalidad del docente $(\mathrm{M}=4,22 ; \mathrm{DT}=0,50)$. Este resultado apunta a un mayor grado de acuerdo por parte del alumnado con el primer tipo de competencias, aquellas relacionadas con el dominio de los conocimientos y herramientas para el ejercicio de la práctica docente. El estadístico $t$ de Student para muestras relacionadas reflejó que estas diferencias eran estadísticamente significativas $(t(104)=5,102 ; p<0,001)$.

En la figura 2 se presentan las medias para cada uno de las $10 \mathrm{com}$ ponentes de la escala "El buen docente ha de tener" para hombres y mujeres. Al igual que se hizo en el apartado anterior, con el fin de analizar posibles diferencias entre chicos y chicas en su grado de acuerdo tanto en los 10 componentes como en cada uno de los dos factores obtenidos, se utilizó el estadístico de contraste $t$ de Student para muestras independientes.

Este estadístico reveló la existencia de diferencias estadísticamente significativas en tener actitud inclusiva $(t(95,77)=-2,197$;
Unas características de personalidad especiales

Carisma y capacidad de persuasión

Conocimiento de metodologías diversas

Pasión por enseñar

Espíritu crítico

Actitud inclusiva

Autoridad

Manejo de las tecnologías de la información y la comunicación

Formación psicopedagógica de la etapa evolutiva implicada

Formación generalista y específica

Mujer

Hombre

Espíritu de formación continua

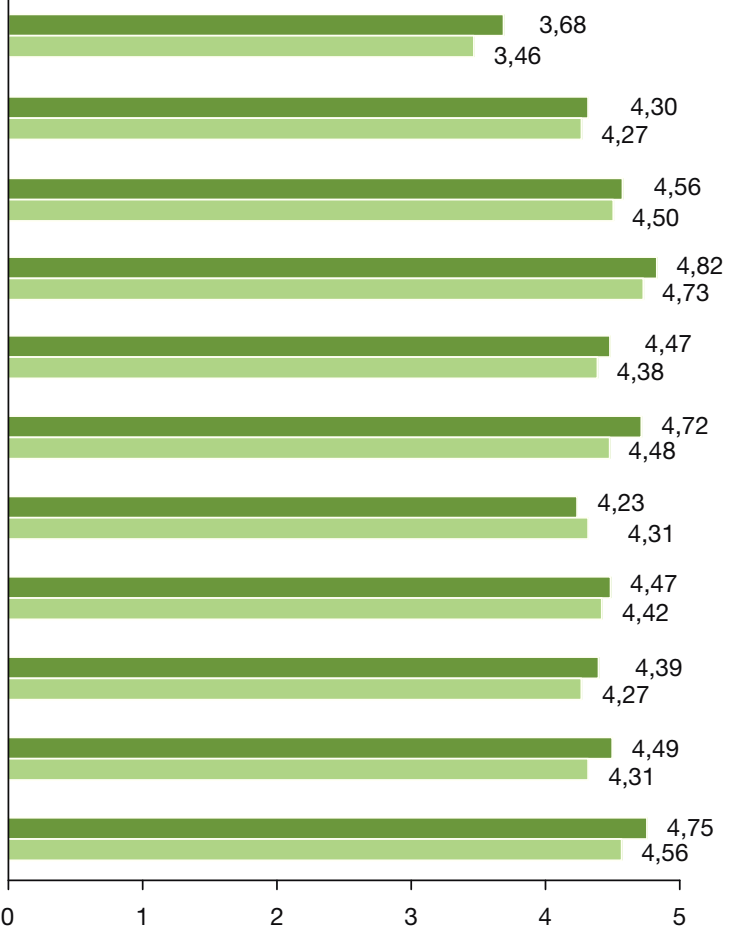

Figura 2. Comparación de medias en los componentes de la escala "El buen docente ha de tener" en función del sexo. 
Tabla 7

Medias y desviaciones típicas en los factores de la escala "El docente ha de tener" según el sexo

\begin{tabular}{lllllll}
\hline Sexo & \multirow{2}{*}{.$^{0}$} & \multicolumn{2}{l}{ Competencias instrumentales } & & \multicolumn{2}{l}{ Personalidad del docente } \\
\cline { 3 - 4 } & & M & DT & & M & DT \\
\hline Hombre & 48 & 4,41 & 0,42 & & 4,20 & 0,51 \\
Mujer & 57 & 4,52 & 0,44 & & 4,26 & 0,50 \\
\hline
\end{tabular}

$p<0,05)$, obteniendo las mujeres mayores puntuaciones que los hombres. Asimismo se encontró una tendencia según la cual las chicas mostraban mayor grado de acuerdo con el ítem tener espíritu de formación continua $(t(85,80)=-1,889 ; p=0,062)$. No se hallaron diferencias significativas en función del sexo en los demás elementos.

En la tabla 7 se presentan las medias y las desviaciones típicas obtenidas por hombres y mujeres en las dos categorías: competencias instrumentales y espíritu formativo, y personalidad del docente. El estadístico $t$ de student no reveló la existencia de diferencias significativas $(p<0,05)$ entre el grado de acuerdo manifestado por chicos y chicas en las dos dimensiones, competencias instrumentales y espíritu formativo, y personalidad del docente.

\section{Discusión}

Los resultados hallados en este estudio muestran cómo la opinión del alumnado de Grado en Educación Primaria sobre las competencias que configuran el perfil del buen docente va en la línea de los resultados obtenidos en estudios previos (Allan et al., 2009; Larrosa, 2010; Pesquero et al., 2008). Estos trabajos señalaban como competencias mejor valoradas aquellas que tenían que ver con el saber implicar a padres y madres en el aprendizaje de sus hijos (es decir, ser capaz de colaborar con las familias), ser capaces de desarrollar en el alumnado valores como la responsabilidad, la solidaridad y la justicia (competencia relacionada con el ítem ser capaz de atender la educación en valores), detectar las dificultades de su alumnado en aprendizajes concretos (muy cercano al ítem ser capaz de favorecer la formación integral del alumnado), o ayudarles a encontrar sentido a los contenidos escolares facilitando el andamiaje cognitivo (que guarda relación con el elemento ser capaz de motivar). Asimismo, Pesquero et al. (2008) constataron que los docentes de Educación Primaria también valoraban las habilidades del maestro para resolver los conflictos (habilidades como ser capaz de escuchar, de establecer límites, ser respetuoso, ser imparcial, ser paciente, etc.), asî como tener vocación y entrega a la profesión (cualidades cercanas a los descriptores pasión por enseñar y tener espíritu de formación continua).

Cabe destacar, como hallazgo de especial interés, que de los datos obtenidos de los ítems del cuestionario que recogen las cualidades susceptibles de configurar el perfil docente han derivado dos escalas diferenciadas que poseen índices de fiabilidad adecuados, las cuales contienen y amplían las cualidades que integran la división de competencias establecida tanto por Casero (2010) como por Armengol et al. $(2007,2011)$.

La primera escala, que determina fundamentalmente el ser del docente, contiene la esencia del talante que ha de caracterizarle para constituirse en un profesional de la educación de calidad. En esta dimensión se agrupan, a su vez, dos subescalas. Por un lado, la que congrega las condiciones necesarias en el dominio de las habilidades que se precisan para el ejercicio de la función docente, como es la capacidad para establecer límites, para colaborar con las familias, para motivar, para favorecer la formación integral, para atender a la educación en valores, así como el hecho de ser creativo, paciente e imparcial. Por otro lado, la que se integra por aquellas competencias afectivo-emocionales que se refieren a la capacidad para gestionar y controlar la esfera afectiva y emocional inherente al ejercicio de la práctica docente, como la capacidad de escucha, el consejo a los alumnos, la capacidad de adaptación permanente a los cambios, la afectividad, la empatía, el respeto y el ser amigo de sus alumnos.

La segunda escala alude esencialmente al tener del docente y en ella se insertan dos subescalas. Una recoge aquellos factores que conciernen al dominio de conocimientos y herramientas que se precisan para la actividad docente, así como la tendencia permanente a la formación por parte del maestro, como es el caso de poseer espíritu de formación continua, gozar de formación generalista, específica y psicopedagógica de la etapa evolutiva implicada, manejar las tecnologías de la información y la comunicación, tener un espíritu crítico y conocer diversas metodologías. Otra engloba los aspectos relacionados con el carácter y el temperamento del docente, como es el caso de la autoridad, la pasión por enseñar, el carisma y la capacidad de persuasión y, finalmente, la posesión de unas características de personalidad especiales.

Estas cuatro categorías sobre el ser y el tener del docente comparten parecido con la clasificación realizada por Casero (2010) que diferenciaba, en primer lugar, aquellos aspectos de competencia formal -saber y saber hacer-, que estarían relacionados tanto con las competencias para saber hacer como con las competencias instrumentales-espíritu formativo, halladas en el presente estudio; y en segundo lugar, aquellas cuestiones más personales -saber ser-, que guardarían relación con las competencias afectivo-emocionales y la personalidad del docente.

Asimismo, es importante destacar que la tipología basada en cuatro grupos de cualidades obtenidas en el presente trabajo es también análoga a la establecida por Armengol et al. (2007, 2011), que diferenciaba tres tipos de competencias: instrumentales, emocionales y sociales. En este sentido, las competencias para el saber hacer y las competencias instrumentales-espíritu de formación podrían considerarse tanto competencias instrumentales (dominio de los conocimientos y las herramientas necesarias para desarrollar el ejercicio de la práctica educativa) como sociales (saber colaborar con otros profesionales, así como mostrar un comportamiento orientado al grupo y al entendimiento interpersonal); las competencias afectivo-emocionales serían similares a las emocionales (saber gestionar y regular constructivamente la dimensión socioafectiva personal y grupal en el ejercicio de la práctica educativa), mientras que la dimensión personalidad del docente incluiría características comunes y transversales a los tres tipos definidos por Armengol et al. (2007, 2011).

Se constata, además, como otra revelación de interés que se sitúa en desacuerdo con algunos autores (Marín et al., 2010; $\mathrm{Ng}$ et al., 2010), que el alumnado se posiciona en mayor sintonía con las competencias instrumentales que con las que hacen referencia a la personalidad y el carisma del maestro, valorando las primeras como fundamentales en la configuración del perfil del buen docente. Es decir, manifiestan mayor grado de acuerdo con aquellas que se refieren al manejo de los saberes y los instrumentos requeridos para la práctica educativa, tales como poseer formación generalista, específica y psicopedagógica del período evolutivo involucrado, conocer diversas metodologías y dominar las tecnologías de la información y la comunicación; competencias que son, en definitiva, susceptibles de adquirir y de educar aunque $a$ priori no se posean. No así en el caso de las que apuntan a la personalidad del docente, que se constituyen en cualidades que forman parte de su impronta y tienen, por ende, mayor dificultad de adquisición y modificación.

Por último, al comparar las medias de cada uno los atributos analizados, se verifica que las alumnas valoran en mayor medida que sus compañeros tres de ellos: la capacidad del docente para favorecer la educación integral -correspondiente a las competencias para el saber hacer-, la capacidad de escucha -perteneciente a las competencias afectivo-emocionales-, y el tener una actitud inclusiva -perteneciente a las competencias instrumentales y espíritu de for- 
mación, si bien, cuando los atributos se comparan globalmente, no se revelan diferencias en función del sexo, pero se descubre una tendencia en la que las mujeres expresan mayor grado de acuerdo con las competencias referentes al saber hacer (ser capaz de colaborar con las familias, de establecer límites, de motivar, de favorecer la educación en valores, de beneficiar la educación integral, así como ser creativo, paciente e imparcial).

La presente investigación ha posibilitado establecer una categorización de las competencias que configuran el perfil docente derivada de la opinión que tiene el alumnado de Grado en Educación Primaria.

No obstante, el presente estudio adolece de una serie de limitaciones. Por un lado, se estima que si se llevase a cabo una triangulación metodológica combinando la técnica cuantitativa utilizada (autoinforme) con otra de índole cualitativa (p. ej., grupo de discusión) se obtendría una mayor riqueza de matices en las conclusiones. Por otro lado, sería conveniente incrementar el número de alumnos y universidades participantes, de forma que los resultados pudiesen generalizarse a la población universitaria española de estudios de Grado en Educación.

Además, al no disponer de estudios previos sobre diferencias de género no pueden compararse nuestros resultados sobre este aspecto, por lo que se considera interesante indagar en un futuro al respecto. Si estas diferencias se verificasen, pondrían de manifiesto la necesitad de adoptar una perspectiva de género en la formación de los futuros maestros.

Se considera que, de este modo, esta profesión puede beneficiarse del establecimiento de unas directrices de actuación en la formación de los futuros maestros situadas a favor de la calidad docente, por lo que estas cuestiones han de aplazarse a la prospectiva que nos brinda el presente estudio.

Dado que se comprueba que la categorización derivada del presente estudio no sólo coincide sino que, además, amplía las que ofrece la bibliografía analizada sobre el tema en cuestión, se propone enfatizar aquellos contenidos de la asignatura Prácticas Escolares que guardan relación con las competencias que conforman el perfil docente puestas de manifiesto, no solo a nivel teórico sino, sobre todo, desde la perspectiva más vivencial y experiencial.

Por un lado, han de realizarse visitas a instituciones del ámbito de la educación formal y no formal, de muy variada idiosincrasia; de este modo se fomenta la actitud crítica, el espíritu de formación permanente y la conciencia de necesidad de educación integral.

Por otro lado, ha de estimularse la reflexión sobre la transferencia que posibilitan las materias cursadas durante el Grado a la realidad de la práctica docente, utilizando diversas estrategias didácticas (p. ej., role-playing, trabajo cooperativo, debates, utilización del cine como recurso didáctico, etc.) que impliquen acercamiento a la realidad educativa actual, con el fin conseguir una integración entre el saber teórico y el práctico, ayudar a la toma de decisiones en situaciones educativas complejas y contribuir al diseño y la aplicación de programas; cuestiones criticadas por el alumnado relacionado con el ámbito de la educación como asignaturas pendientes al culminar su formación (Cardona, 2011). Se lograría, de este modo, un mejor conocimiento de metodologías diversas y se incitaría al espíritu crítico, fomentando la capacidad de escucha, la empatía y el respeto, e impulsando la creatividad y la motivación.

Asimismo, ha de profundizarse en el conocimiento del alumnado de educación infantil y primaria, sus características psicosociales, su nivel cognitivo, su nivel afectivo-emocional, su interacción con el ambiente, sus experiencias de vida y escolares, su capacidad para solucionar problemas, su creatividad, etc. Con técnicas como la dramatización, el estudio de casos y los dilemas morales se pretende intensificar la formación psicopedagógica de la etapa evolutiva implicada, el espíritu crítico, la capacidad para motivar, la empatía y el respeto.

Igualmente, se considera que algunas de las competencias subrayadas a lo largo de este artículo se trabajan en profundidad en diferentes asignaturas cursadas a lo largo de la carrera. En concreto, se destaca la de ser capaz de colaborar con las familias (asignatura Sociedad, Familia y Tutoría), ser capaz de educar en valores y atender a la educación emocional como vía para la resolución adecuada de los conflictos (asignatura de Educación para la Convivencia), tener una formación tanto generalista como específica (todas las asignaturas), tener una formación psicopedagógica de la etapa evolutiva implicada (Psicología del Desarrollo, Didáctica General en Educación Primaria, Sistemas Educativos. Fundamentos e Historia de la Educación Contemporánea), ser capaz de favorecer la educación integral (Educación Inclusiva y Respuesta a la Diversidad, Trastornos del Desarrollo y Dificultades de Aprendizaje), entre otras. En esta línea, se propone alentar al profesorado responsable de estas y otras materias a coordinar esfuerzos con el fin de optimizar los resultados.

\section{Referencias bibliográficas}

Allan, J., Clarke, K., y Jopling, M. (2009). Effective teaching in higher education: perceptions of first year undergraduate students. International Journal of Teaching and Learning in Higher Education, 21, 362-372.

Armengol, C., Canals, M., Gairin, J., Jariot, M., Massot, M., Rodríguez, M., et al. (2007). Model de Pràcticum Integrador (MPI), material de suport per a la millora de les competències profesional. Sabadell: A l'Abast.

Armengol, C., Castro, D., Jariot, M., Massot, M., y Sala, J. (2011). El Practicum en el Espacio Europeo de Educación Superior (EEES): mapa de competencias del profesional de la educación. Revista de Educación, 354, 71-98.

Cardona, J. (2011). Hacia la mejora de la formación práctica del estudiante de pedagogía en la UNED. Educación XX1, 14, 303-330.

Casero, A. (2010). ¿Cómo es el buen profesor universitario según el alumnado? Revista Española de Pedagogía, 246, 223-242.

Cifuentes, P. (2008). Panorama de la Educación Superior en Europa en el marco del proceso de Bolonia. En J. R. Flecha (Coord.), El proceso de Bolonia y la Enseñanza Superior en Europa. Madrid: Instituto Superior de Estudios Europeos.

Fidalgo, R., y García, J. (2007). Las directrices del Espacio Europeo de Educación Superior en el marco legislativo del sistema universitario español. Aula Abierta, 35, 35-48.

Galvis, R. V. (2007). De un perfil docente tradicional a un perfil docente basado en competencias. Acción Pedagógica, 16, 48-57.

García, E. (2010). Competencias éticas del profesor y calidad de la educación. Revista Electrónica Interuniversitaria de Formación del Profesorado, 13, 29-41.

González Tirados, R. M., y González Maura, V. (2007). Diagnóstico de necesidades y estrategias de formación docente en las universidades. Revista Iberoamericana de Educación, 43, 1-14.

Guth, J. (2006). The Bologna process: The impact of higher education reform on the structure and organization of doctoral programmes in Germany. Higher Education in Europe, 31, 327-338.

Gutiérrez-García, C., Pérez-Pueyo, Á., Pérez-Gutiérrez, M., y Palacios, A. (2011). Percepciones de profesores y alumnos sobre la enseñanza, evaluación y desarrollo de competencias en estudios universitarios de formación de profesorado. Cultura $\mathcal{E}$ Educación, 23, 499-514.

Jordán, J. A. (2011). Disposiciones esenciales de los profesores en las relaciones con sus alumnos desde una perspectiva ética-pedagógica. Educación XX1, 14(1), 59-87.

Larrosa, F. (2010). Vocación docente versus profesión docente en las organizaciones educativas. Revista Electrónica Interuniversitaria de Formación del Profesorado, 13, 43-51.

Liesa, M., y Vived, E. (2010). El nuevo prácticum del Grado de magisterio. Aportaciones de alumnos y profesores. Estudios sobre Educación, 18, 201-218.

Marín, V., Latorre, M. J., y Blanco, F. J. (2010). Las competencias profesionales de la titulación de magisterio vistas desde la óptica del alumno receptor. Estudio del caso de Educación Primaria. Estudios sobre Educación, 19, 219-235.

$\mathrm{Ng}, \mathrm{W}$., Nicholas, H., y Williams, A. (2010). School experience influences on pre-service teachers' evolving beliefs about effective teaching. Teaching and Teacher Education, 26, 278-289.

Pertegal, M. L., Castejón, J., y Martínez, M. A. (2011). Competencias socioemocionales en el desarrollo profesional del maestro. Educación XX1, 14(2), 237-260

Pesquero, E., Sánchez, M. E., González, M., Martín, R., Guardia, S., Cervelló, J., et al (2008). Las competencias profesionales de los maestros de primaria. Revista Española de Pedagogía, 241, 447-466.

Rodicio, M. L., e Iglesias, M. (2011). La formación en competencias a través del prácticum. Un estudio piloto. Revista de Educación, 354, 99-124.

Rodríguez, J., Álvarez, V., Gil, J., y Romero, S. (2011). Necesidades del profesorado de la Universidad de Sevilla respecto a la enseñanza que requiere el EEES. Cultura $\mathcal{E}$ Educación, 23, 323-340.

Zabalza, M. A. (2003). Competencias docentes del profesorado universitario. España: Narcea.

Zabalza, M. A. (2007). Guía para la planificación didáctica de la docencia universitaria en el marco del EEES. Santiago de Compostela: Universidad de Santiago de Compostela.

Zabalza, M. A. (2012). Las competencias en la formación del profesorado: de la teoría a las propuestas prácticas. Tendencias Pedagógicas, 20, 5-32.

Zahonero, A., y Martín, M. (2012). Formación integral del profesorado: hacia el desarrollo de competencias personales y de valores en los docentes. Tendencias Pedagógicas, 20, 51-70. 